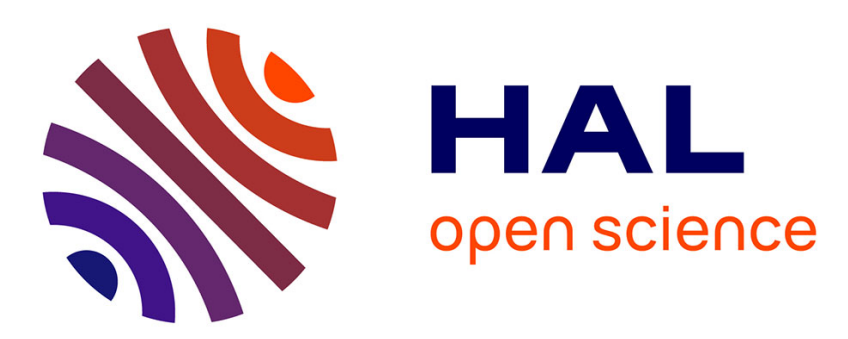

\title{
Tool wear and cutting forces under cryogenic machining of titanium alloy (Ti17)
}

\author{
Sabrine Trabelsi, Anne Morel, Guenael Germain, Zoubeir Bouaziz
}

\section{To cite this version:}

Sabrine Trabelsi, Anne Morel, Guenael Germain, Zoubeir Bouaziz. Tool wear and cutting forces under cryogenic machining of titanium alloy (Ti17). International Journal of Advanced Manufacturing Technology, 2016, 91 (5-8), pp.1493-1505. 10.1007/s00170-016-9841-4 . hal-02283242

\section{HAL Id: hal-02283242 \\ https://hal.science/hal-02283242}

Submitted on 10 Sep 2019

HAL is a multi-disciplinary open access archive for the deposit and dissemination of scientific research documents, whether they are published or not. The documents may come from teaching and research institutions in France or abroad, or from public or private research centers.
L'archive ouverte pluridisciplinaire HAL, est destinée au dépôt et à la diffusion de documents scientifiques de niveau recherche, publiés ou non, émanant des établissements d'enseignement et de recherche français ou étrangers, des laboratoires publics ou privés. 


\title{
Tool wear and cutting forces under cryogenic machining of titanium alloy (Ti17)
}

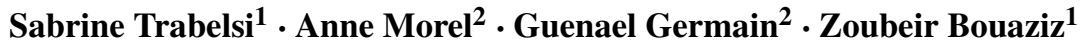

\begin{abstract}
Titanium alloy is well known for its difficulty to machine, owing to the important "tool wear" phenomenon. Machining assistance is an interesting solution to lengthen the tool lifetime. In this study, we focused on the effect of cryogenic assistance-during machining of Ti17—on the tool wear and cutting forces for different combinations of cutting speed, feed rate and depth of cut. Compared to conventional lubrication, cryogenic support lengthens the tool life for all tested conditions and has no significant influence on cutting force. A comparison of the cryogenic effect and high-pressure water jet assistance is also presented.
\end{abstract}

Keywords Titanium alloy $\cdot$ Cryogenic assistance $\cdot$ Tool wear $\cdot$ Cutting force $\cdot$ High pressure water jet assistance

\section{Introduction}

Titanium alloys have high strength, high chemical reactivity and a low thermal conductivity, causing a high temperature at the tool/chip interface. The high temperature accelerates the tool wear which results in a short tool life [1]. To overcome this problem, effective cooling of the interface

Sabrine Trabelsi

trabelsi4sabrine@gmail.com

Anne Morel

anne.morel@ensam.eu

Guenael Germain

guenael.germain@ensam.eu

1 National School of Engineers of Sfax, MFAP, Sfax 3038, Tunisia

2 Arts et Métiers ParisTech, LAMPA, 2 bd du Ronceray, 49035 Angers Cedex, France tool/chip is recommended. The cryogenic support allows a significant cooling by nitrogen liquid, $\left(-196^{\circ} \mathrm{C}\right)$ which makes it possible to improve the tool life when machining titanium alloys, thus avoiding the degradations of the tool among which can be mentioned abrasion, adhesion and diffusion, which are intensified when temperature increases [2]. Wang and Rajurkar studied the effect of the cryogenic assistance on tool lifetime and surface roughness when machining hard-to-machine materials with different tool inserts [3].

They carried out machining of:

- reaction bonded silicon nitride (RBSN) with three different polycrystalline cubic boron nitride tools (CBN50 of Sandvik and VC734 and VC722 of Valenite);

- titanium alloy Ti6Al4V, tantalum and Inconel 718 with H13A tungsten carbide tool from Sandvik.

They found that the tool life is lengthened and the surface roughness is improved with cryogenic assistance for all combinations of tool inserts / materials studied. For the titanium alloy Ti6Al4V, which was machined at $1 \mathrm{~mm}$ depth of cut, with a feed rate of $0.2 \mathrm{~mm} / \mathrm{rev}$ and a cutting speed of 2.2 $\mathrm{m} / \mathrm{s}$, the flank wear $\mathrm{Vb}$ was equal to $1.1 \mathrm{~mm}$ in conventional machining and dropped to $0.22 \mathrm{~mm}$ with cryogenic support after $46 \mathrm{~mm}$ of machining. Surprisingly, no significant change for the three force components was observed.

Dhananchezian and Pradeep Kurmar compared the influence of cryogenic support to that of conventional lubrication when machining titanium alloy Ti6Al4V at a depth of cut of $1 \mathrm{~mm}$, a feed rate of $0.159 \mathrm{~mm} / \mathrm{rev}$ and a different cutting speed of 27,63, and $97 \mathrm{~m} / \mathrm{min}$. A modified tool projecting cryogenic liquid on the cutting face and on the primary and secondary flank faces was used. It was noticed that the temperature decreases at the speed of $97 \mathrm{~m} / \mathrm{min}$ from 504 ${ }^{\circ} \mathrm{C}$ to $192{ }^{\circ} \mathrm{C}$. After $5 \mathrm{~min}$ of machining at a speed of 63 
Table 1 Chemical composition of Ti17 (\%)

\begin{tabular}{llllll}
\hline $\mathrm{Ti}$ & $\mathrm{Al}$ & $\mathrm{Mo}$ & $\mathrm{Cr}$ & $\mathrm{Zr}$ & $\mathrm{Sn}$ \\
\hline 82.5 & 5.16 & 4.08 & 4.06 & 2.01 & 2.06 \\
\hline
\end{tabular}

$\mathrm{m} / \mathrm{min}$, the flank wear was 536 and $370 \mu \mathrm{m}$ in conventional lubrication and cryogenic support, respectively [4].

The literature contains other works dealing with the application of the cryogenic support on the rake face or the flank face or the rake and flank face simultaneously, and the optimal position of the nozzle during the machining of Ti6Al-4V alloy. For a depth of cut of $1.27 \mathrm{~mm}$, a feed rate of $0.254 \mathrm{~mm} / \mathrm{rev}$ and a cutting speed of $1,1.5,2$, and $2.5 \mathrm{~m} / \mathrm{s}$, respectively, it was found that the best injection position of the cryogen liquid is obtained with an injection nozzle between the chip and the rake face of the tool. This assistance increases the cutting and the thrust force and reduces the feed force because it lowers the friction coefficient at the tool-chip interface. In addition, the shear angle increases and the shear band thickness decreases [5]. This article aims at investigating the effect of cryogenic support on the Ti17 titanium alloy for two operating conditions, namely roughing and finishing tests, and its impact on the tool lifetime, cutting force and surface roughness. The results of the cryogenic support are then compared to those of conventional lubrication and high-pressure water jet support. A particular attention is drawn to the degradation modes of the tool.

\section{Experimental setup}

The material used is the titanium alloy Ti17 (also called Ti-5Al-2Sn-2Zr-4Mo-4Cr). The chemical composition and the mechanical properties are presented in Tables 1 and 2 . The Ti17 is a mixed alloy of $\alpha$ and $\beta$ phases (Fig. 1). Its transus temperature is $880{ }^{\circ} \mathrm{C}$. Above this temperature, only the phase $\beta$ exists. It is mostly used in aeronautic field for its mechanical properties such as resistance to high temperatures, which makes it very difficult to machine.

Table 2 Mechanical properties of the material

\begin{tabular}{ll}
\hline Ultimalte Tensile strength (MPa) & 1110 \\
\hline$\sigma_{p 02 \%}$ & 1020 \\
$\mathrm{E}(\mathrm{GPa})$ & 114 \\
Elongation (\%) & 5 \\
\hline
\end{tabular}

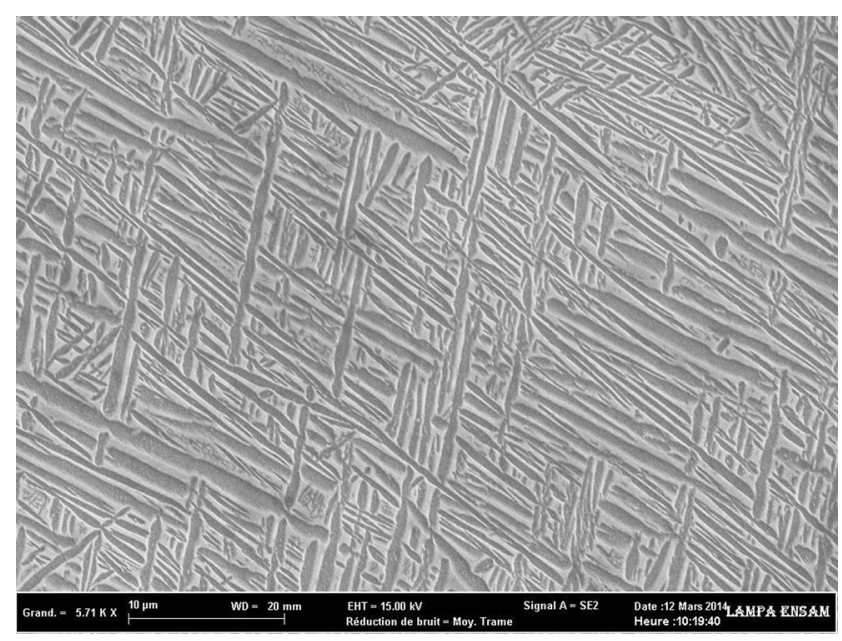

Fig. 1 SEM observation of the microstructure of the titanium alloy Ti17

The machining tests were carried on a lathe-turning machine "LEADWELL LTC25iL" (2500 rev/min and a maximum power of 24 kilowatts). A three-component force sensor (9275B) was placed on the tool to acquire the three force components. A charge amplifier (Kistler 5019B) was used to convert the electrical charge yield by the piezoelectric sensor into proportional voltage. The analog signals output are amplified by a charge amplifier (Kistler 5019B). Thereafter, they are passed to an analog/digital converter. The evolution of the effort over time is provided by the Catman Easy software. A Seco JetStream PCLNR 2525M12 tool was used with CNMG120412-23 H13A insert showing a geometry defined by a rake angle of $7^{\circ}$, a flank angle of $6^{\circ}$, an edge radius of $30 \mu \mathrm{m}$ and a nose radius of $1.2 \mathrm{~mm}$. The nitrogen jet is provided by two nozzles of $1.7 \mathrm{~mm}$ in diameter that project the liquid on the rake face of the tool (Fig. 2). A tank of 180 liters provides the nitrogen liquid supply at a pressure of 12 bars. The cryogenic fluid is supplied to the tool with insulated pipes and a phase separator fitted next to the tool.

The change of cutting parameters (feed rate, depth of cut and cutting speed) results in different tool degradation modes as well as a change of the tool life. An experimental campaign was conducted with a cutting speed of 50 and 90 $\mathrm{m} / \mathrm{min}$, a feed rate of 0.1 and $0.3 \mathrm{~mm} / \mathrm{rev}$, and a depth of cut of 1.5 and $3 \mathrm{~mm}$. The combination of these parameters was determined by a complete experimental design made by $2^{3}$ experiments to study the effect of each parameter on the tool wear, its life and the cutting force. Table 3 summarizes the test data.

For each test, the analysis focused on:

- the evolution of the tool flank wear and crater;

- the tool degradation modes; 
Fig. 2 Experimental setup

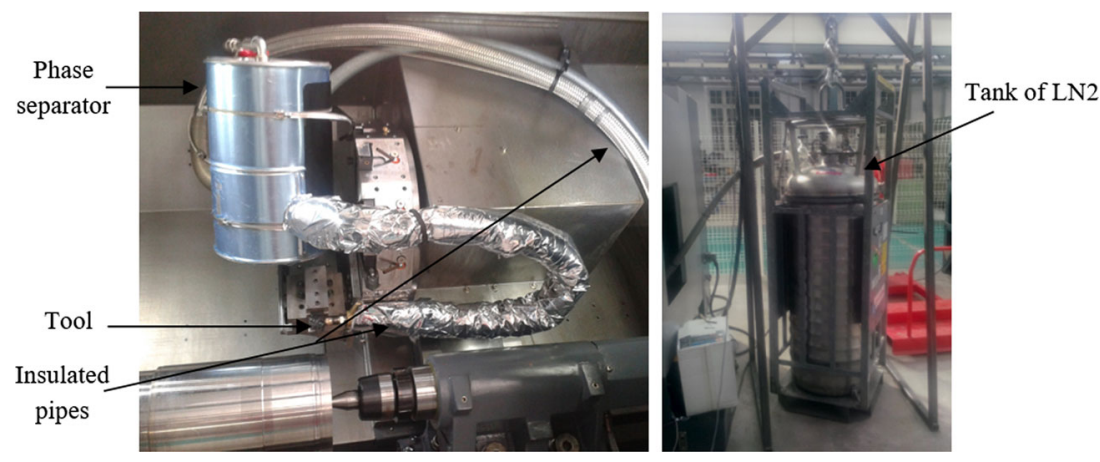

Fig. 3 Evolution of the flank wear as a function of depth of cut, feed rate and cutting speed
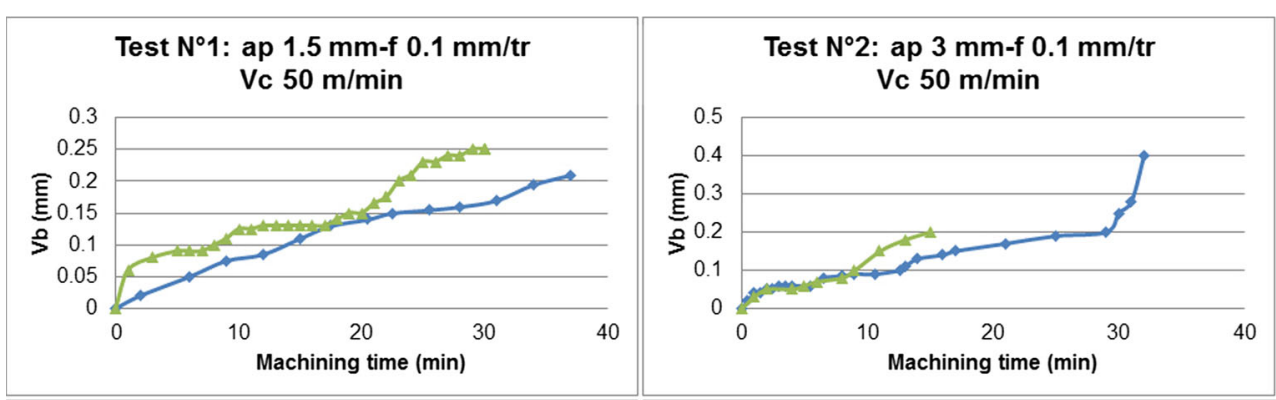

Test №3: ap $1.5 \mathrm{~mm}-\mathrm{f} 0.3 \mathrm{~mm} / \mathrm{tr}$ Vc $50 \mathrm{~m} / \mathrm{min}$

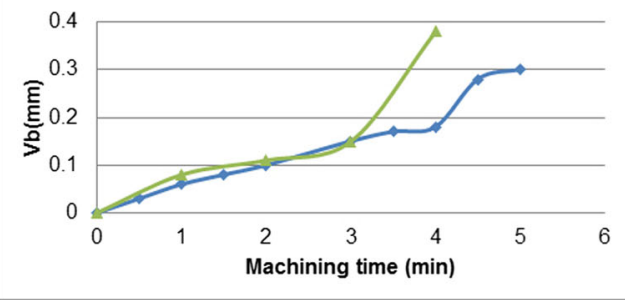

Test N4: ap $3 \mathrm{~mm}-\mathrm{f} 0.3 \mathrm{~mm} / \mathrm{tr}$ Vc $50 \mathrm{~m} / \mathrm{min}$
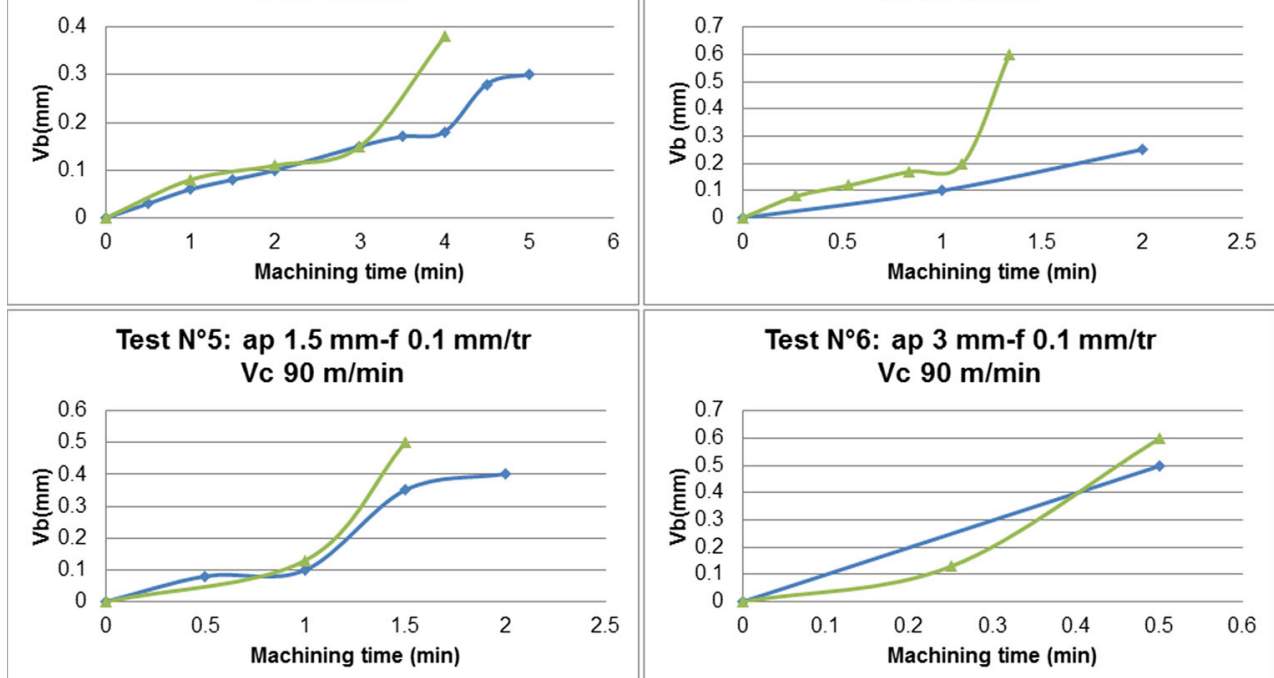

Test $\mathrm{N}^{\circ} 6$ : ap $3 \mathrm{~mm}-\mathrm{f} 0.1 \mathrm{~mm} / \mathrm{tr}$ Vc $90 \mathrm{~m} / \mathrm{min}$

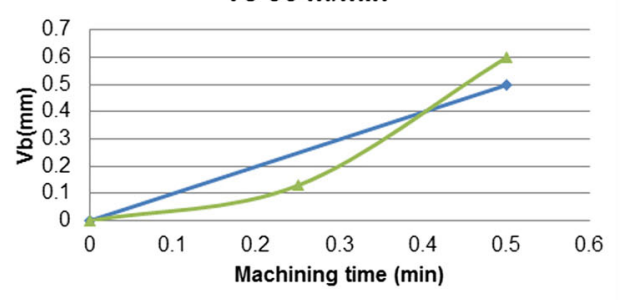

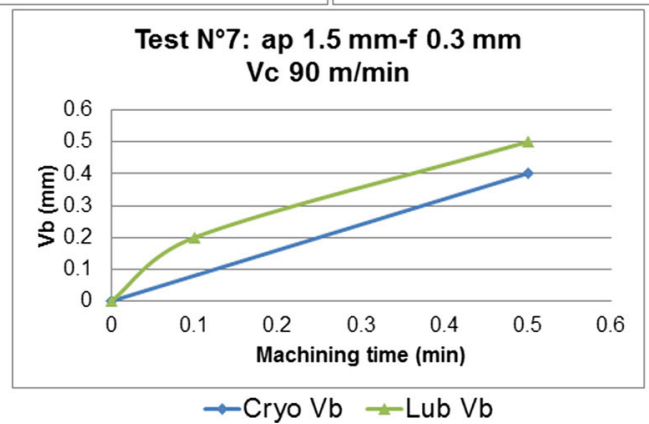


Table 3 Tests performed on experimental design

\begin{tabular}{llll}
\hline Test $\mathrm{N}^{\circ}$ & ap $(\mathrm{mm})$ & $\mathrm{f}(\mathrm{mm} / \mathrm{rev})$ & $\mathrm{Vc}(\mathrm{m} / \mathrm{min})$ \\
\hline 1 & 1.5 & 0.1 & 50 \\
2 & 3 & 0.1 & 50 \\
3 & 1.5 & 0.3 & 50 \\
4 & 3 & 0.3 & 50 \\
5 & 1.5 & 0.1 & 90 \\
6 & 3 & 0.1 & 90 \\
7 & 1.5 & 0.3 & 90 \\
8 & 3 & 0.3 & 90 \\
\hline
\end{tabular}

- the chemical elements present on the tool insert;

- the surface roughness ( $\mathrm{Ra}$ and Rt criterion);

- the three cutting force components.

\section{Results and discussions}

\subsection{Tool Life}

Figure 3 shows the evolution of the flank wear for the first seven tests of the experimental design. Test $\mathrm{N}^{\circ} 8$ (ap $3 \mathrm{~mm}-$ f $0.3 \mathrm{~mm} / \mathrm{rev}-\mathrm{Vc}_{\mathrm{c}} 90 \mathrm{~m} / \mathrm{min}$ ) has been removed because the edge collapses after 10 seconds of machining. For ap $1.5 \mathrm{~mm}$-f $0.1 \mathrm{~mm} / \mathrm{rev}-\mathrm{Vc} 50 \mathrm{~m} / \mathrm{min}$ (Test $\mathrm{N}^{\circ} 1$ ), in conventional lubrication, there is an increase of the flank wear, then occurs a steady state between 12 and $17 \mathrm{~min}$ at a flank wear of $0.13 \mathrm{~mm}$, followed by a gradual wear increase again. Under cryogenic conditions, on the contrary, wear evolves constantly. For ap $3 \mathrm{~mm}-\mathrm{f} 0.1 \mathrm{~mm} / \mathrm{rev}-\mathrm{Vc}$ $50 \mathrm{~m} / \mathrm{min}$ (test $\mathrm{N}^{\circ}$ ), at first, the curves obtained in both lubrication and cryogenic assistance evolve in very similar ways. From $10 \mathrm{~min}$ of machining, the tool wear in lubrication increases more rapidly to reach $0.2 \mathrm{~mm}$ after 15 min of machining, whereas in cryogenic conditions it continues to increase gradually up to $0.2 \mathrm{~mm}$ for $29 \mathrm{~min}$ of machining.

Table 4 Tool life for different cutting parameters
For ap $1.5 \mathrm{~mm}-\mathrm{f} 0.3 \mathrm{~mm} / \mathrm{rev}-\mathrm{Vc} 50 \mathrm{~m} / \mathrm{min}$ (Test $\mathrm{N}^{\circ} 3$ ), up to 3 min of machining, the evolution of the flank wear with conventional lubrication and cryogenic assistance are very close, before diverging strongly. For ap $3 \mathrm{~mm}-\mathrm{f} 0.3$ $\mathrm{mm} / \mathrm{rev}-\mathrm{Vc} 50 \mathrm{~m} / \mathrm{min}$ (Test $\mathrm{N}^{\circ} 4$ ), from the beginning of machining, the flank wear is slightly greater with the nitrogen liquid. However, after $1.1 \mathrm{~min}$, the wear in lubrication becomes much more important.

We can therefore conclude that if the machining condition becomes more severe, the divergence between the two curves begins at a lower machining time. For the cutting speed of $90 \mathrm{~m} / \mathrm{min}$, the evolution of the two curves becomes very close with almost the same slopes. The following table (Table 4) shows the lifetimes for each cutting condition and the gain in tool life using the cryogenic assistance compared to the conventional lubrication.

Gain $=\frac{\text { tool } \quad \text { life }(\text { cryogenic })-\text { tool life }(\text { lubrication })}{\text { tool } \quad \text { life }(\text { lubrication })} * 100$

The tool end-of-life criterion is defined by a flank wear of $\mathrm{Vb}=0.2 \mathrm{~mm}$. It is worth noting that the cryogenic cooling lengthens the tool life regardless of the cutting parameters, but its efficiency differs depending on the used parameters. Indeed, the tool life decreases if the feed, the depth of cut or the cutting speed increases.

\begin{tabular}{llll}
\hline Condition & $\begin{array}{l}\text { Tool life (min) } \\
\text { Conv. lubrication }\end{array}$ & Cryogenic & Gain (\%) \\
\hline ap 1.5-f 0.1-Vc 50 & 23 & 35 & 52 \\
ap 3-f 0.1-Vc 50 & 15 & 29 & 93 \\
ap 1.5-f 0.3-Vc 50 & 3.21 & 4.1 & 27 \\
ap 3-f 0.3-Vc 50 & 1.1 & 1.75 & 59 \\
ap 1.5-f 0.1-Vc 90 & 1.09 & 1.2 & 10 \\
ap 3-f 0.1-Vc 90 & 0.13 & 0.17 & 30.7 \\
ap 1.5-f 0.3-Vc 90 & 0.1 & 0.12 & 20 \\
ap 3-f 0.3-V c90 & 0.02 & 0.033 & 65 \\
\hline
\end{tabular}


Table 5 Geometrical parameters of the chip

\begin{tabular}{llllllllll}
\hline $\mathrm{Vc}$ & $\mathrm{f}$ & $\mathrm{ap}$ & condition & $\phi$ & $\operatorname{Dc}(\mu \mathrm{m})$ & $\mathrm{f}_{\mathrm{seg}}(\mathrm{KHz})$ & $\mathrm{D}_{\min }(\mu \mathrm{m})$ & $\mathrm{D}_{\max }(\mu \mathrm{m})$ & $\mathrm{Fc}(\mathrm{N})$ \\
\hline 50 & \multirow{2}{*}{0.1} & \multirow{2}{*}{1.5} & Cryo & 36.58 & 109.22 & 7.62 & 142.415 & 224.94 & 436 \\
& & & Lub C & 76.3 & 153 & 5.44 & 88 & 150.6 & 429 \\
50 & \multirow{2}{*}{0.3} & \multirow{2}{*}{3} & Cryo & 31.1 & 169.6 & 4.91 & 197.1 & 350.5 & 1893 \\
& \multirow{2}{*}{0.1} & \multirow{2}{*}{1.5} & Lub C & 51.5 & 277.5 & 3 & 367 & 731.7 & 1846 \\
90 & & Cryo & 36.4 & 68.1 & 22 & 72.9 & 127.7 & 429 \\
& & & Lub C & 38.5 & 110.6 & 13.56 & 122.8 & 264.9 \\
\hline
\end{tabular}

A complementary study was conducted to better understand the effect of each parameter on the tool life (Fig. 4). In order to take into account the specific nature of the different controlling parameters, it was chosen to represent their effects for a factor increase of $1 \mathrm{~mm}$ for the depth of cut, $0.1 \mathrm{~mm} / \mathrm{rev}$ for the feed rate and $10 \mathrm{~m} / \mathrm{min}$ for the cutting speed. As a result, the standardized effects are given by:

Standardized effect $($ eap $)=($ Eap $/ 1.5) / \mathrm{N} \quad($ ap varies in the range of 1.5 to $3.0 \mathrm{~mm}$, so $1.5 \times 1 \mathrm{~mm}$ )

Standardized effect $(\mathrm{ef})=(\mathrm{Ef} / 2) / \mathrm{N} \quad(\mathrm{f}$ varies in the range of 0.1 to $0.3 \mathrm{~mm} / \mathrm{rev}$, so $2 \times 0.1 \mathrm{~mm} / \mathrm{rev}$ )

Standardized effect $(\mathrm{eVc})=(\mathrm{EVc} / 4) / \mathrm{N} \quad(\mathrm{Vc}$ varies in the range of 50 to $90 \mathrm{~m} / \mathrm{min}$, so $4 \times 10 \mathrm{~m} / \mathrm{min}$ )

With $\mathrm{N}=\mid$ Eap $/ 1.5|+| \mathrm{Ef} / 2|+| \mathrm{EVc} / 4 \mid$

Eap, Ef and EVc are respectively the effect of depth of cut, the effect of feed rate and the effect of cutting speed.

The feed rate shows to be the most influential parameter on the tool life in both cryogenic and conventional lubrication. The second affecting parameter is the cutting speed and the last is the depth of cut. However, this depth of cut is the first responsible criterion causing the greatest difference between the two techniques, considering the tool life. When the cutting speed increases, the heat generation becomes

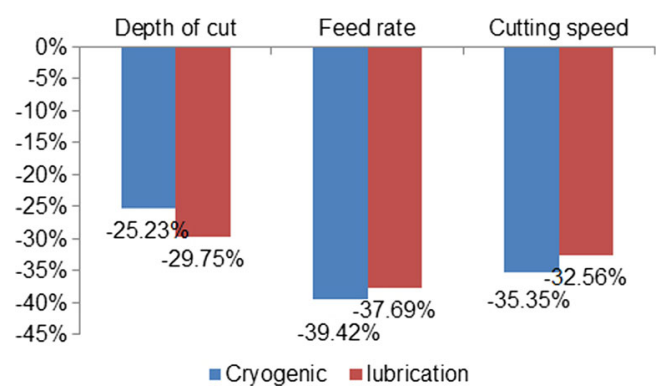

Fig. 4 Standardized effects of cutting parameters
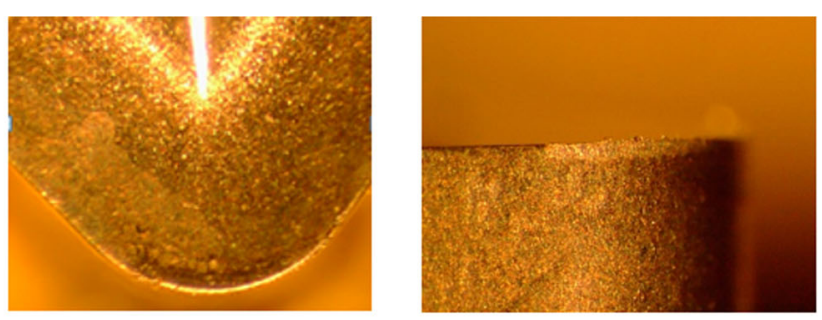

ap $1.5 \mathrm{~mm}-\mathrm{f} 0.1 \mathrm{~mm} / \mathrm{rev}$
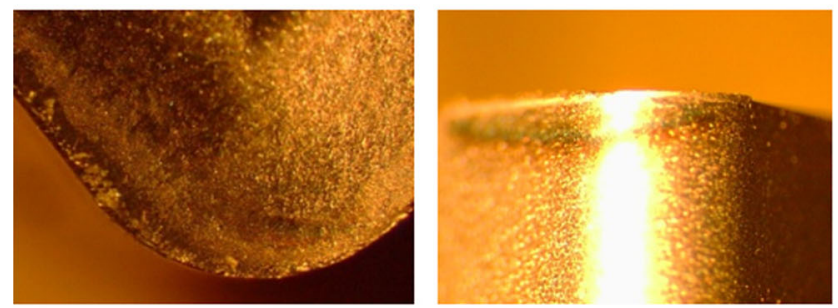

ap $3 \mathrm{~mm}-\mathrm{f} 0.1 \mathrm{~mm} / \mathrm{rev}$

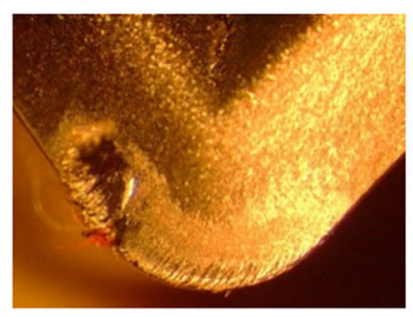

ap $1.5 \mathrm{~mm}-\mathrm{f} 0.3 \mathrm{~mm} / \mathrm{rev}$
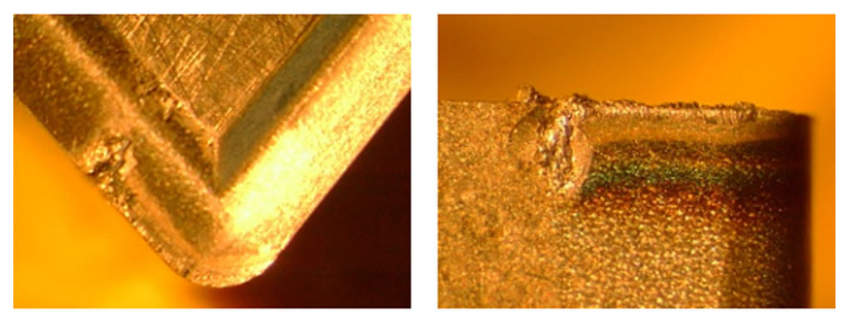

ap $3 \mathrm{~mm}-\mathrm{f} 0.3 \mathrm{~mm} / \mathrm{rev}$

Fig. 5 Microscopic observations of the tool wear at 1 minute of machining with cryogenic assistance (Vc 50 m/min) 
Fig. 6 Microscopic

observations of the tool wear in cryogenic assistance at 1 minute of machining at $\mathrm{Vc} 50 \mathrm{~m} / \mathrm{min}-\mathrm{f}$ $0.1 \mathrm{~mm} / \mathrm{rev}$ a ap $1.5 \mathrm{~mm}$ at 33 min and $\mathbf{b}$ ap $3 \mathrm{~mm}$ at $30 \mathrm{~min}$

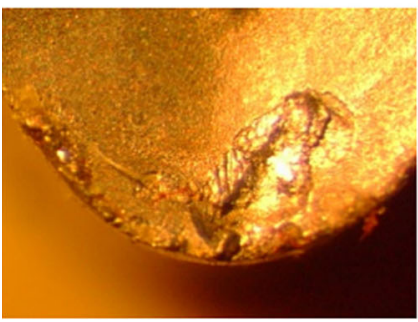

(a)

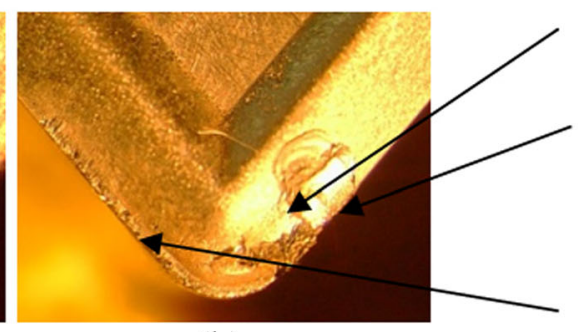

(b)
Crater wear

Secondary cutting

edge

\section{Primary cutting}

edge more important in the machining area, and when the feed rate increases, the contact length increases. The material having a low thermal conductivity, the temperature at the tool/chip interface becomes very high when one of these parameters is increased. The cryogenic assistance becomes hence unable to cool the tool to the tip.

Berhingam et al. carried out the same kind of study on a Ti-6Al-4V alloy regarding the influence of the depth of cut and the feed rate at a cutting speed of $85 \mathrm{~m} / \mathrm{min}$. It was noted that the feed rate is the most influential parameter on the tool life at a constant cutting speed. The authors explain this phenomenon by a temperature (and a wear) increase due to a higher heat generation when the feed rate increases [6].

It is clear that the cryogenic assistance increases the tool life for all the combinations of cutting parameters. For a cutting speed of $50 \mathrm{~m} / \mathrm{min}$, the gain in the tool life with a cryogenic machining increases if the depth of cut increases. On the other hand, it decreases with the increase of the feed rate. There is no doubt the cryogenic assistance effectively cools the tool for high depth of cut but it cannot compensate, in a similar way, for the heating of the tool due to the increase of the feed rate.

For the cutting speed of $90 \mathrm{~m} / \mathrm{min}$, the gain due to the cryogenic support increases if the feed rate or the depth of cut increases. However, at this cutting speed, tool lifetime is very short, because the generated temperatures are very important. Therefore, the cutting speed and the feed rate must be adequately chosen to machine the Ti17 alloy.

The following pictures (Fig. 5) show the rake and the flank faces and their associated wears after 1 minute of machining with the cryogenic assistance for the various machining configurations. For low feed rates, the flank wear is regular and crater wear is not visible. In contrast, for a high feed rate, the wear is much greater on the flank face and on the rake face where a crater wear is clearly visible. In addition, for this feed, a notch wear can also be noticed. When the feed rate increases, the thickness of the chip increases and the force gets higher. The heat generation is more important because it leads to decreasing the tool hardness and accelerating the wear phenomenon [2].
After $1 \mathrm{~min}$ of machining at $\mathrm{f} 0.1 \mathrm{~mm} / \mathrm{rev}$ - ap $1.5 \mathrm{~mm}$, the crater wear is not visible at the end of life of the tool. After about 30 min of machining, a built up edge (BUE) is formed and the crater wear is significant (Fig. 6). For the depth of cut of $3 \mathrm{~mm}$, the crater wear is observable at one minute.

The crater wear is formed in the direction of chip evacuation after the titanium builds up on the cutting face, and then it is removed by peeling. At a feed rate of $0.3 \mathrm{~mm} / \mathrm{rev}$, from 1 minute of machining, a notch is formed and the crater is localized at the primary cutting edge (Figs. 7 and 8).

Besides the adhesive wear and the abrasion, characteristic of the conventional machining, the wear mode is a creep deformation of the cutting edge, accelerating its collapse especially for greater feed rates [7]. This degradation mode is not observed in cryogenic machining assistance as temperature decreases.

\subsection{Cutting forces}

The cutting forces in machining with the cryogenic assistance are compared to those of conventional lubrication (Fig. 9).

For all the configurations, the cutting forces in conventional lubrication are slightly lower than those obtained with cryogenic support except for the case of ap $1.5 \mathrm{~mm}$ f $0.3 \mathrm{~mm} / \mathrm{rev}$ and $\mathrm{Vc} 90 \mathrm{~m} / \mathrm{min}$. This last tendency can be explained by the rapid wear of the tool when increasing the cutting speed and the feed rate at the same time.

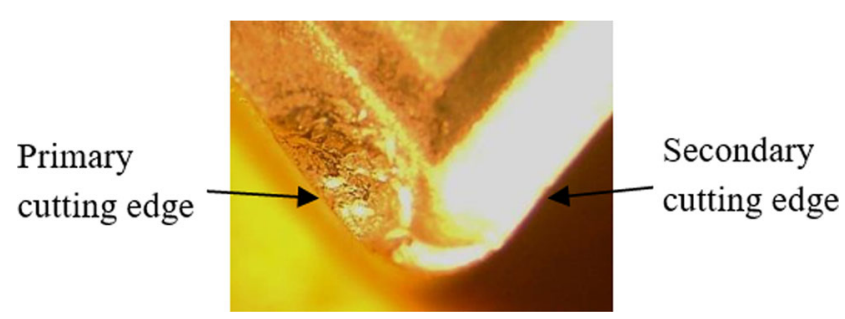

Fig. 7 Microscopic observations of the tool wear at 1 min of machining with cryogenic assistance (Vc $50 \mathrm{~m} / \mathrm{min}$-ap $1.5 \mathrm{~mm}-\mathrm{f} 0.3 \mathrm{~mm} / \mathrm{rev}$ ) 
Fig. 8 Flank and rake wear in conventional machining (ap 3 $\mathrm{mm}$-f $0.3 \mathrm{~mm} / \mathrm{rev}-\mathrm{Vc} 50 \mathrm{~m} / \mathrm{min}$ )
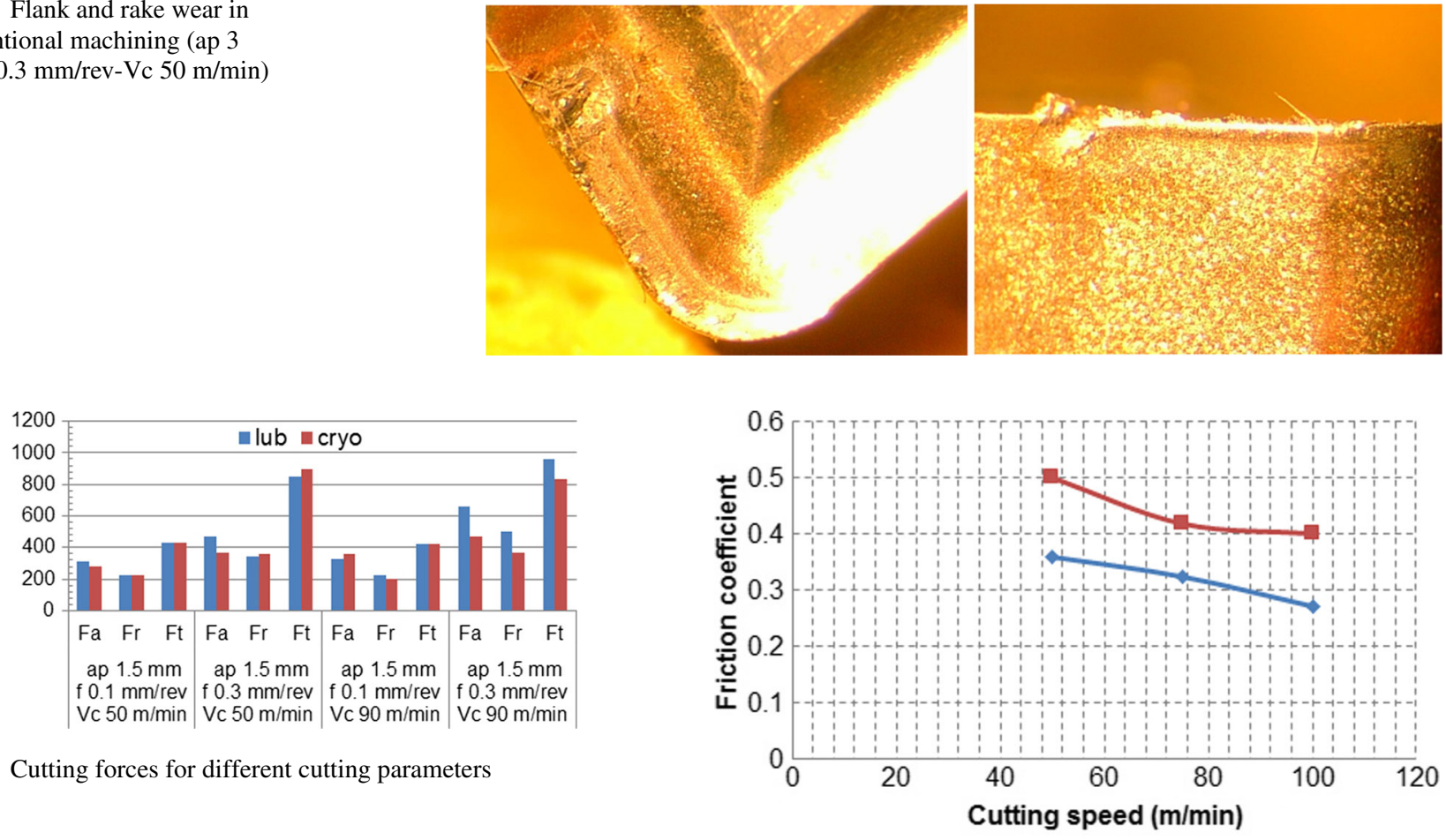

Fig. 9 Cutting forces for different cutting parameters

\section{Cutting speed $(\mathrm{m} / \mathrm{min})$}

$\leadsto \mu$ cryogenic $\rightarrow-\mu$ lubrication

Fig. 12 Friction coefficient evolution

Fig. 10 Description of the tribometer

Fig. 11 Contact between the pin and the work-piece [8]
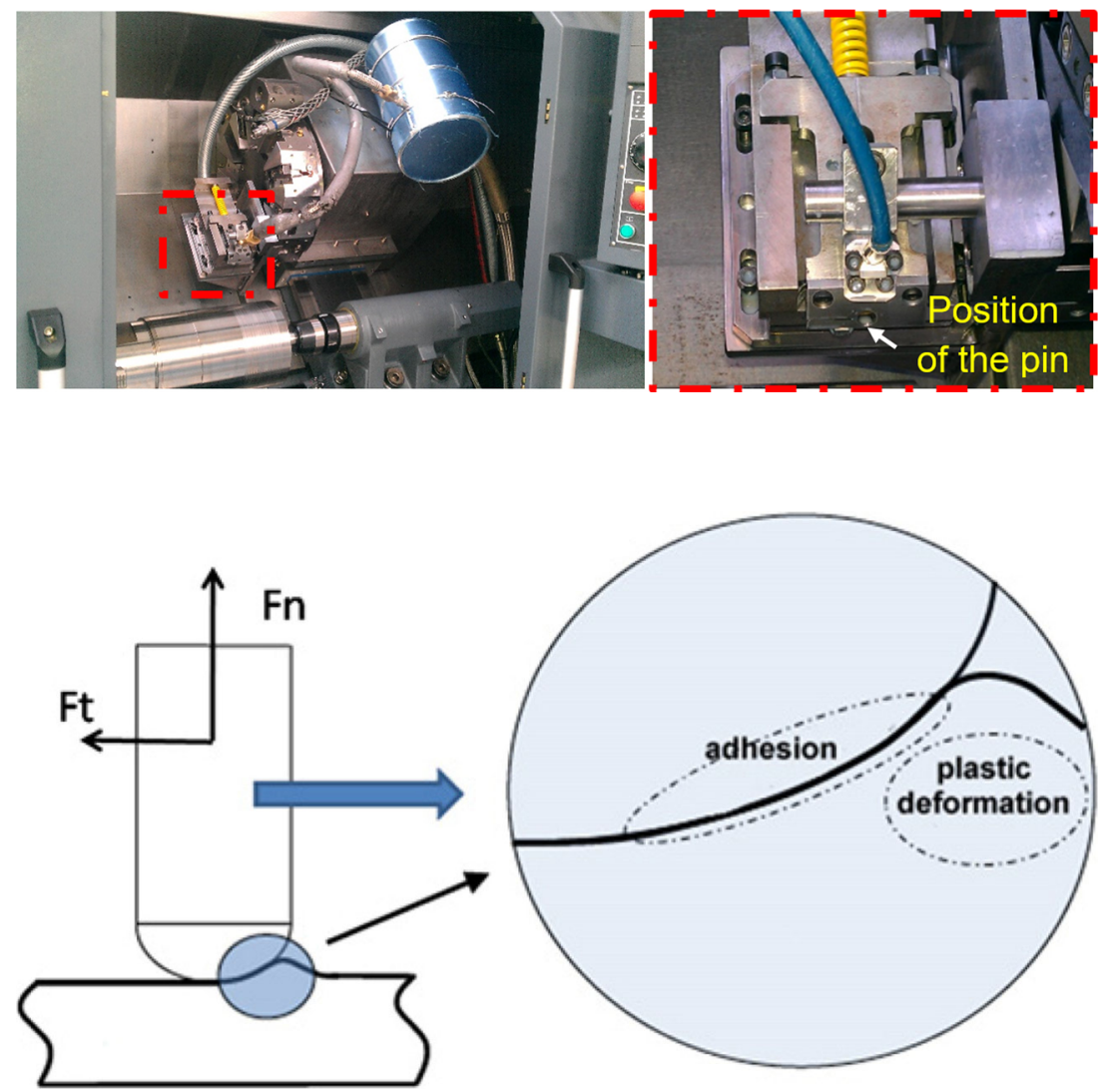
Fig. 13 Microscopic observation of the chips generated
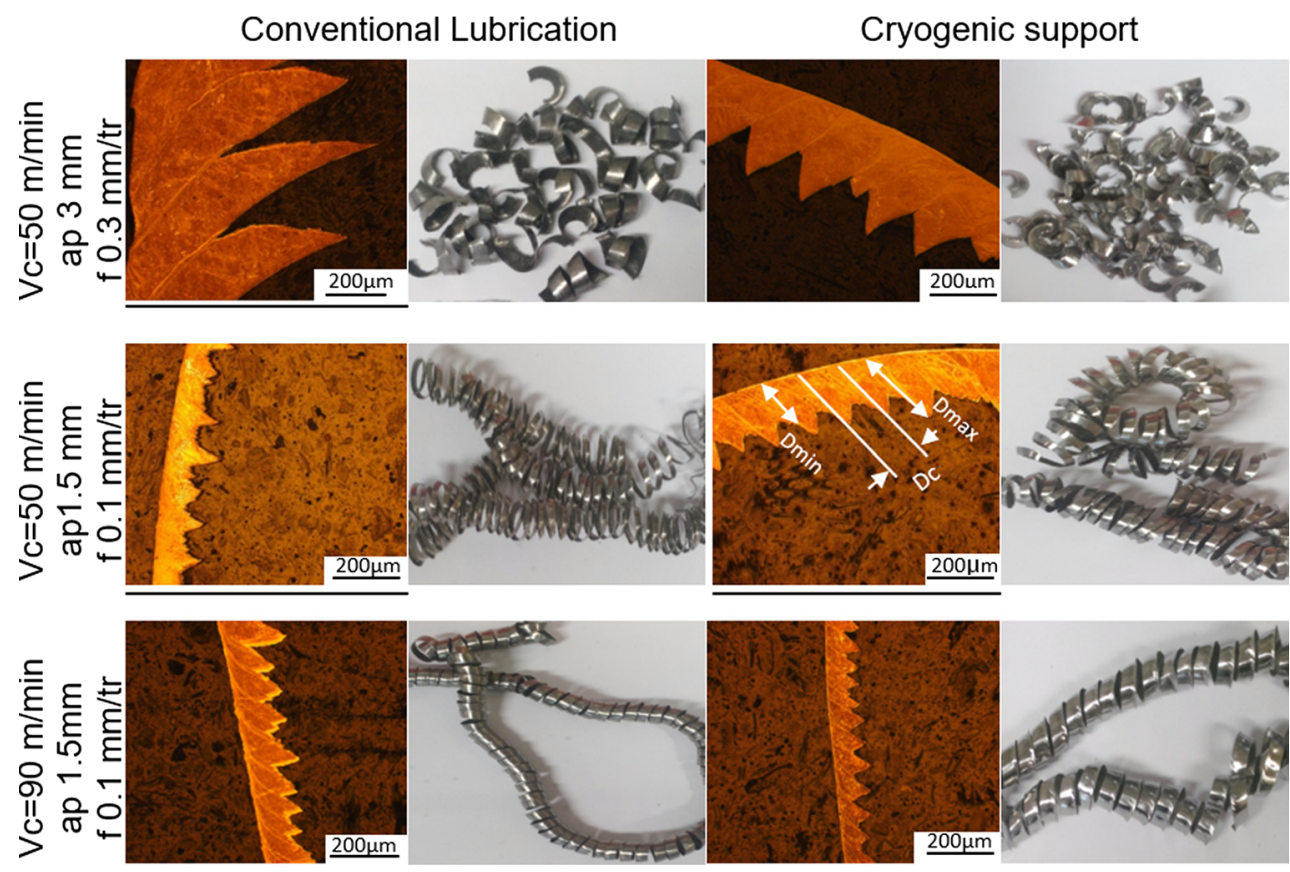

This difference is not significant. The cutting force does not seem to be modified by the cryogenic assistance. The thrust force decreased for all the configurations except for (ap $1.5 \mathrm{~mm}-\mathrm{f} 0.3 \mathrm{~mm} / \mathrm{rev}-\mathrm{Vc} 50 \mathrm{~m} / \mathrm{min}$ ) where the increase is $2.6 \%$ only. The feed force also declined for all the configurations except ap $1.5 \mathrm{~mm}$ - f $0.1 \mathrm{~mm} / \mathrm{rev}-\mathrm{Vc} 90 \mathrm{~m} / \mathrm{min}$ where the increase is $10 \%$. For a better understanding of the evolution of the cutting forces when machining with LN2, friction tests were conducted using an open system tribometer where a pin rubs on the outer surface of a cylindrical part (made of the work material to be machined) in rotation (Fig. 10). Tests were achieved in conventional lubrication and under cryogenic cooling for three different cutting speeds.

In these tests, a carbide pin similar to the grade of the cutting tool rubs at relevant contact pressure and high sliding speed against the work piece Ti17. During the test, normal and tangential forces are measured to determine the friction coefficient by an inverse method. The normal force is set at $200 \mathrm{~N}$.

During the contact between the pin and the work piece, the tangential force is due to friction between the two materials and the plastic deformation of the contact area (Fig. 11).

A numerical simulation of the test was therefore carried out in order to decouple the friction between the two materials and the effect due to the plastic deformation [9]. The coefficients obtained are shown in the following figure
(Fig. 12). The friction test is performed at 3 sliding velocities $\left(V_{s}=50,75,100 \mathrm{~m} / \mathrm{min}\right)$.

The friction coefficient $\mu$ in cryogenic assistance is lower than that in lubrication. For both conditions, the friction coefficient decreases if the cutting speed increases. At a cutting speed of $50 \mathrm{~m} / \mathrm{min}$, the friction coefficient decreases from 0.5 in cryogenic condition to 0.36 in conventional lubrication, corresponding to $28 \%$ decrease, whereas with the speed of $100 \mathrm{~m} / \mathrm{min}$ it decreases from 0.4 to 0.27 , that is to say $32.5 \%$. Thus, the friction coefficient decreases more strongly when the cutting velocity increases. This decrease in friction coefficient should result in decreasing the cutting force. We can also speculate that the decrease in the friction coefficient is compensated by the increase in the

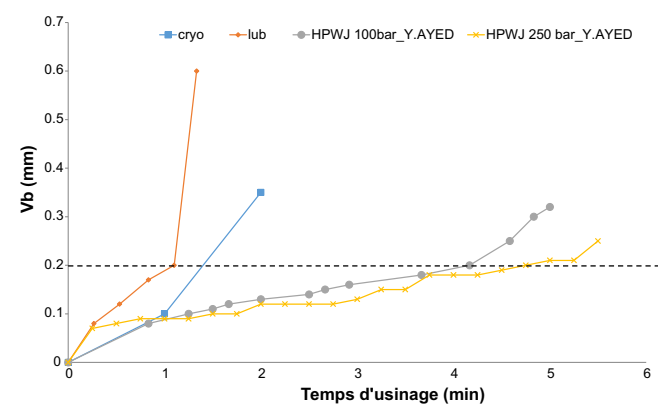

Fig. 14 Evolution of the flank wear (ap $1.5 \mathrm{~mm}-\mathrm{f} 0.1 \mathrm{~mm} / \mathrm{rev}$ ) for various machining assistance 
Fig. 15 Microscopic observation of the rake face of the tool at $\mathbf{a} 1 \mathrm{~min}$ and $\mathbf{b} 2 \mathrm{~min}$ of machining (ap $3 \mathrm{~mm}-\mathrm{f} 0.3$ $\mathrm{mm} / \mathrm{rev}-\mathrm{Vc} 50 \mathrm{~m} / \mathrm{min}$ )

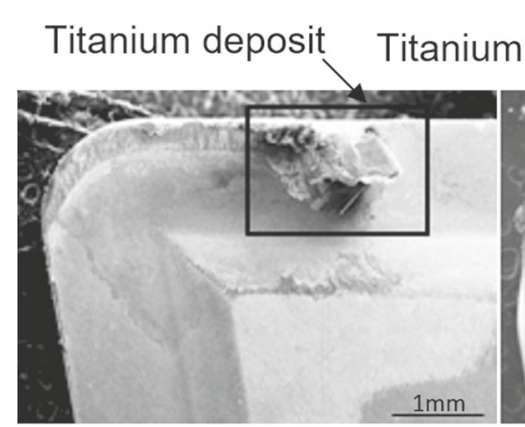

(a)

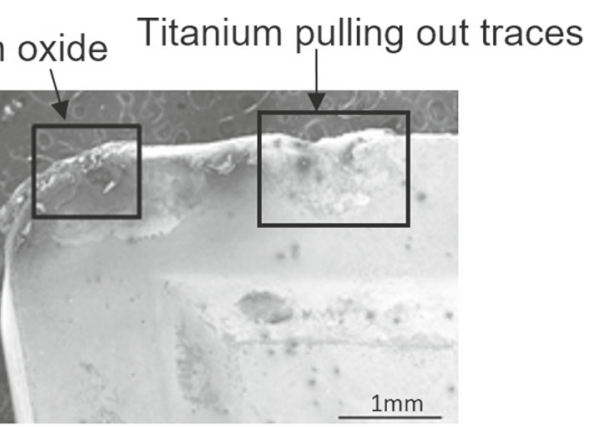

(b) hardness of the work piece material due to the surface cooling by the cryogenic fluid [5]. A complementary study will be performed to confirm or deny this hypothesis.

\subsection{Chip morphology}

For every machining test, the chip was collected and observed. Micrographs were performed to highlight the shear bands. It is noted that the chip is continuous and spiral for a feed rate of $0.1 \mathrm{~mm} / \mathrm{rev}$, and then it becomes fragmented when the feed rate increases at $0.3 \mathrm{~mm} / \mathrm{rev}$.

The color of the chip is darker in conventional lubrication whereas it remains unchanged in cryogenic assistance. This is explained by the occurrence of an oxide layer due to the temperature rise in the first condition. From the micrographs of the chips, the following geometrical parameters of the chips have been identified: $\phi$ : the shear angle; Dc: The distance between two segments of the chip; $\mathrm{F}_{\text {seg }}$ : segmentation frequency; $D_{\min } ; D_{\max }$ (Fig. 13).

$F$ seg $=\frac{V_{c}}{D_{c}}$

The obtained results are summarized in Table 5. For the three cutting conditions, the segmentation frequency has increased and the shear angle has decreased with the application of LN2. The cryogenic assistance decreases the thermal softening and increases the flow stress compared to the conventional lubrication. If the rise of the cutting speed increases the thermal softening and the primary shear angle, then it is logical to expect that the cryogenic cooling decreases the shear angle compared to the conventional lubrication. Microscopic observation of the shear bands shows that their thickness has decreased. For ap 1.5
Fig. 16 Flank face microscopic observation of the tool at a $1 \mathrm{~min}$ and $\mathbf{b} 2$ min of machining (ap 3 $\mathrm{mm}-\mathrm{f} 0.3 \mathrm{~mm} / \mathrm{rev}-\mathrm{Vc} 50 \mathrm{~m} / \mathrm{min}$ )

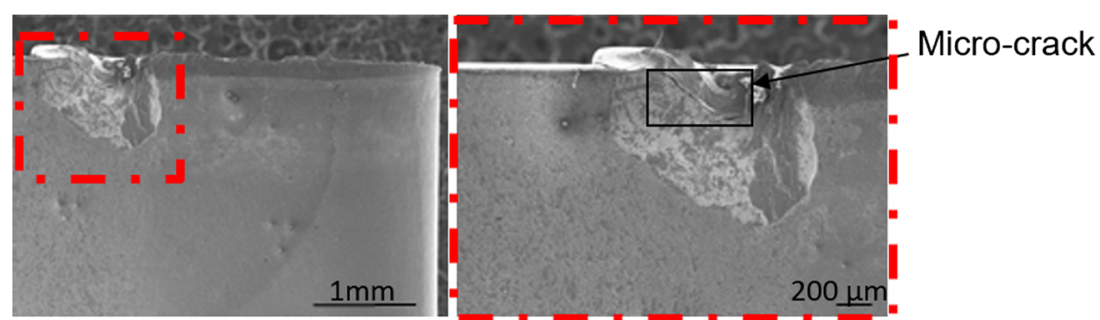

(a)

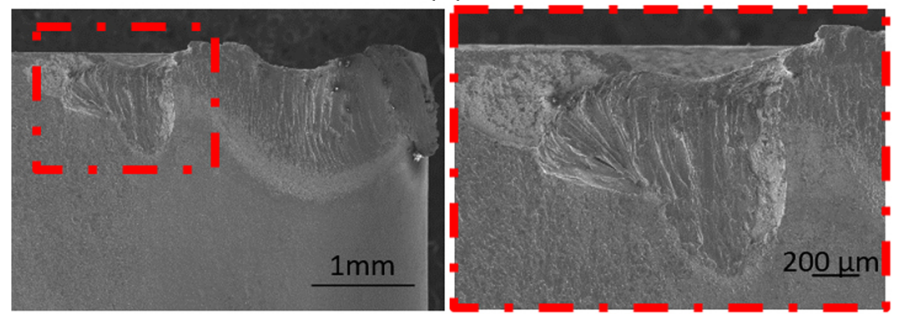

(b) 
mm- f $0.1 \mathrm{~mm} / \mathrm{rev}-\mathrm{Vc} 50 \mathrm{~m} / \mathrm{min}$, the shear band thickness decreased from $2.09 \mu \mathrm{m}$ in conventional lubrication to $1.08 \mu \mathrm{m}$ in cryogenic support; roughly corresponding to $48 \%$ drop. This decrease in thickness can be explained by the higher location of the shear zone due to the reduction of temperature at the tool/chip interface and the reduction of the frictional force between the cutting face and the chip [5].

\section{Comparison of the effect of the cryogenic support to that of the HP water Jet}

In order to go further in the analysis of the cryogenic assistance effect, two machining conditions similar to those of Ayed et al., namely the finishing test (ap $1.5 \mathrm{~mm}-\mathrm{f} 0.1$ $\mathrm{mm} / \mathrm{rev}-\mathrm{Vc} 50 \mathrm{~m} / \mathrm{min}$ ) and the roughing test (ap $3 \mathrm{~mm}-\mathrm{f}$ $0.3 \mathrm{~mm} / \mathrm{rev}-\mathrm{Vc} 50 \mathrm{~m} / \mathrm{min}$ ), were performed on our material. Ayed compared the effect of High-pressure water jet support at 100 and 250 bars to the conventional lubrication for these two operating conditions [7].

\subsection{Roughing tests}

The flank wear in machining with HPWJ assistance 100 bars and with HPWJ assistance 250 bars evolve in a similar way, but they evolve slower than the conventional lubrication and the cryogenic machining. The cryogenic assistance lengthens the tool life from $1.1 \mathrm{~min}$ in conventional lubrication to $1.75 \mathrm{~min}$, which induces a gain of $59 \%$. However, it is less effective than HP water jet, which ensures a lifetime of $4.17 \mathrm{~min}$ at 100 bars and $4.75 \mathrm{~min}$ at 250 bars, which corresponds to a gain of 279 and $331 \%$, respectively (Fig. 14). The tool chemical analysis shows titanium adhesion to the rake and flank faces of the insert. At 2 min, a titanium oxide layer formation can be observed on the rake face, just next to the tip, and adherent titanium is observed on the remainder of the tool (Fig. 15).

This shows that the tip of the tool was not cooled, because for a feed rate of $0.3 \mathrm{~mm} / \mathrm{rev}$, the contact length tool/chip increases. The nitrogen liquid is therefore unable to reach the tip of the tool to provide a suitable cooling, whereas the mechanical action of water jet allows the fragmentation of the chip and, therefore, a reduction in the contact length between the chip and the tool, which cools the cutting edge more effectively.

Titanium adhesion was also noticed on the flank face after one minute of machining. A micro-crack, which leads to a rupture of the edge, was also visible (Fig. 16).

The temperature increases with both the depth of cut and feed rate. When it is high, diffusion and adhesion are the two most dominant mechanisms. At this temperature, titanium is very reactive with many chemical elements, especially cobalt which is the binder of the cutting inserts. This chemical affinity leads to a dissolution of cobalt in the titanium, which induces loosening of the tungsten carbide grains of the insert [10, 11]. The cooling must hence be significant to the tip to prevent the edge rapid wear.

\subsection{Finishing tests}

For the condition (ap $1.5 \mathrm{~mm}$ - f $0.1 \mathrm{~mm} / \mathrm{rev}-\mathrm{Vc} 50 \mathrm{~m} / \mathrm{min}$ ), the lifetime of the tool insert is 35 and $23 \mathrm{~min}$ in cryogenic and conventional lubrication, respectively, that is to say a gain of $52 \%$. With the HP water jet assistance at 100 bars, the tool life is $33 \mathrm{~min}$ (43\%). However, it decreases to $23.8 \mathrm{~min}(3.8 \%)$ with a pressure jet of 250 bars. In this configuration, the feed rate is small (unlike the rough configuration), and the cryogenic cooling is more effective as the contact length tool/chip is low (Fig. 17).

The gain is slightly more significant in cryogenic conditions than with the high-pressure water jet assistance. On the other hand, the HP water jet mechanical action allows the fragmentation of the chip, which is not the case for the cryogenic assistance. For better understanding of the evolution of wear in cryogenic assistance, microscopic observations and chemical analyzes were performed on the tool insert. It was noticed that up to 15 min of machining the wear is uniform, the titanium clusters are adherent on both the rake and the flank faces (Fig. 18).

Up to $30 \mathrm{~min}$ of machining, there is no deep crater but chemical analysis reveals the existence of titanium deposits, which are removed in $33 \mathrm{~min}$ accentuating the crater formed in the direction of the flow of the chip by adhesive wear (Fig. 19).

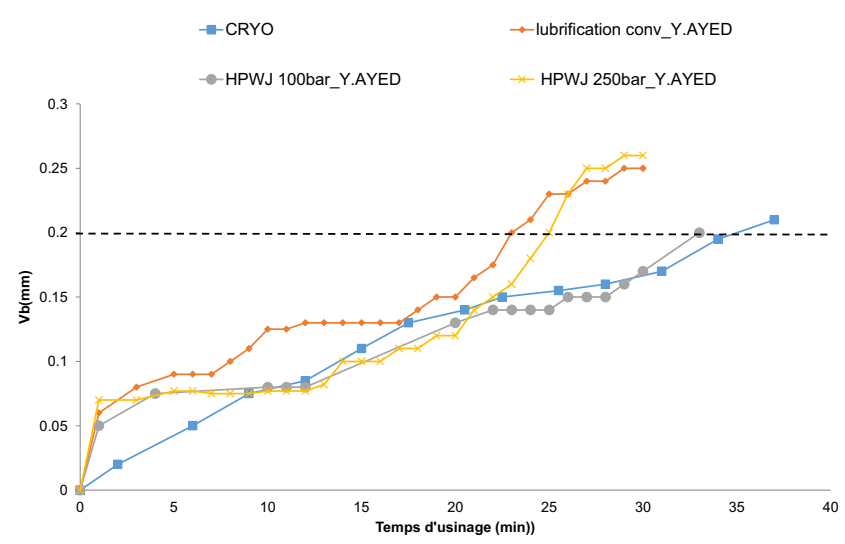

Fig. 17 Flank wear evolution (ap $1.5 \mathrm{~mm}-\mathrm{f} 0.1 \mathrm{~mm} / \mathrm{rev}-\mathrm{Vc} 50 \mathrm{~m} / \mathrm{min}$ ) 


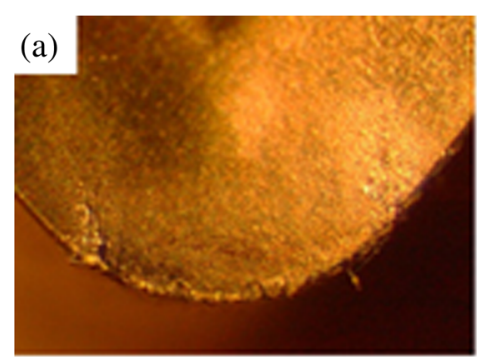

(b)
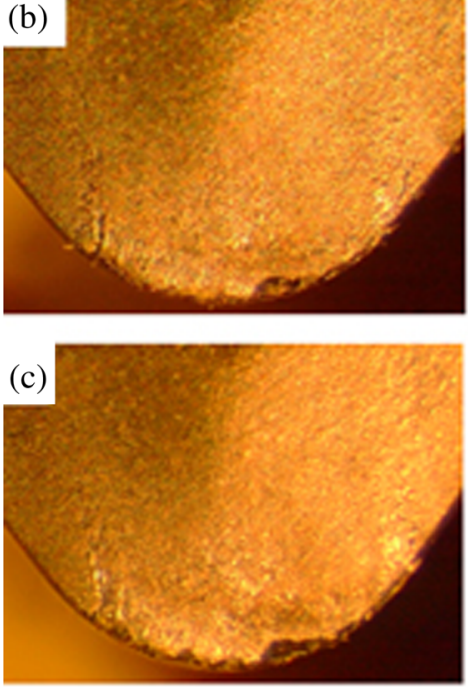

(d)

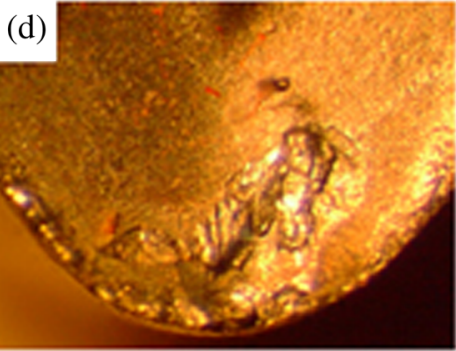

(e)

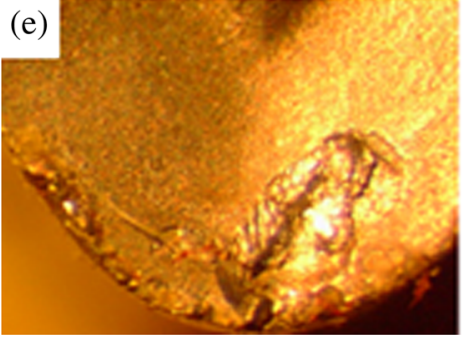

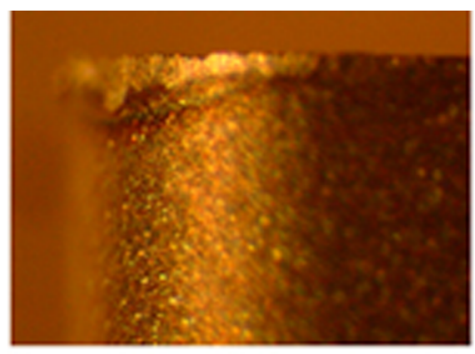
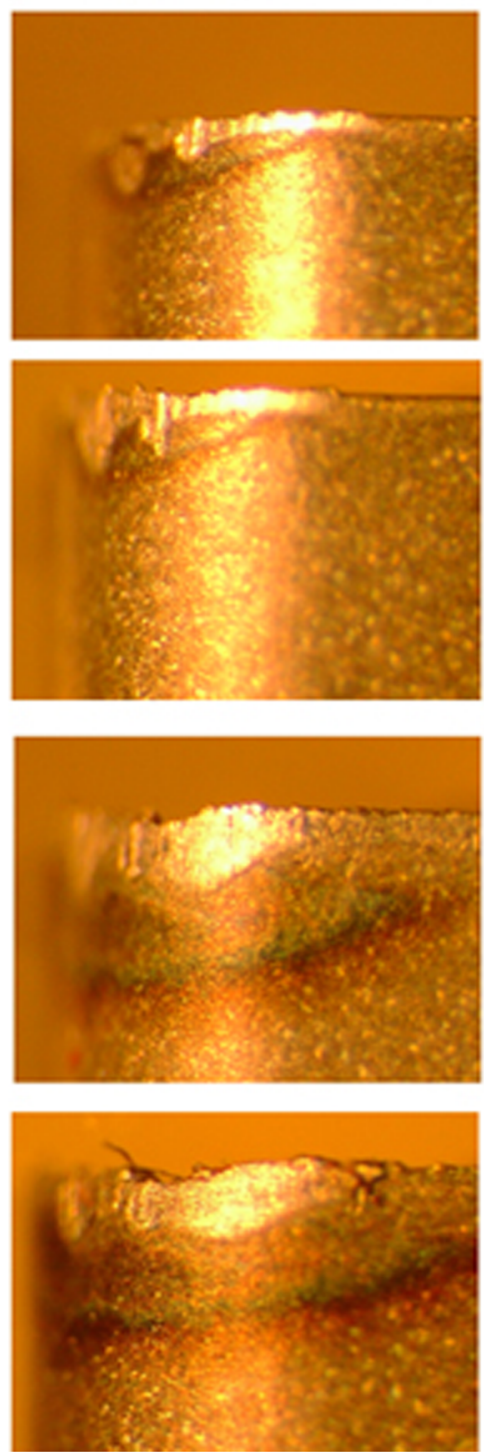
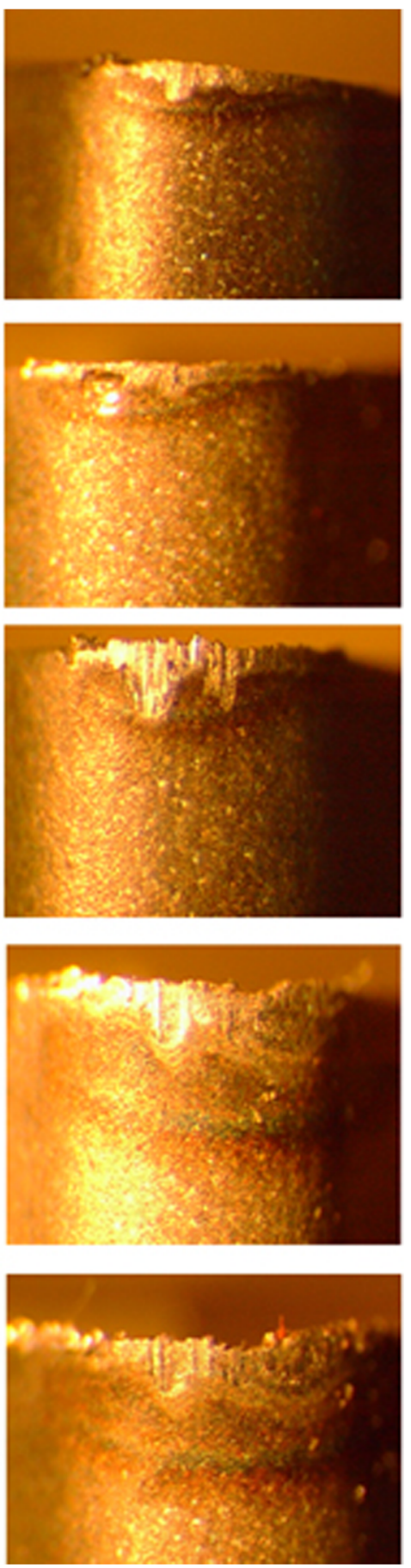

Fig. 18 Tool wear with cryogenic assistance at a $15 \mathrm{~min}, \mathbf{b} 25 \mathrm{~min}, \mathbf{c} 30 \mathrm{~min}$, d $32 \mathrm{~min}$, e $33 \mathrm{~min}$ for ap $1.5 \mathrm{~mm}$ and f $0.1 \mathrm{~mm} / \mathrm{rev} \mathrm{Vc} 50 \mathrm{~m} / \mathrm{min}$

The streaks on the flank face show the abrasive wear which results from tearing of welded titanium clusters. An SEM analysis of chemical elements for the first cutting condition (ap $1.5 \mathrm{~mm}-\mathrm{f} 0.1 \mathrm{~mm} / \mathrm{rev}-\mathrm{Vc} 50 \mathrm{~m} / \mathrm{min}$ ) shows the existence of titanium on the flank face. This layer welded to the flank face is torn, causing tool wear. It is the adhesive wear (Fig. 20).
In finishing, the surface roughness is as important as the tool life in insuring the desired quality. To this end, the roughness of the part was raised (Fig. 21).

Unlike in conventional lubrication, the surface roughness with the cryogenic assistance does not increase linearly but remains constant between 0.4 and $0.5 \mu \mathrm{m}$ up to $30 \mathrm{~min}$. It increases with increasing $\mathrm{Vb}$. In conventional lubrica- 
Fig. 19 Tool wear with cryogenic assistance at a 30 $\mathrm{min}, \mathbf{b} 33 \mathrm{~min}$ at ap $1.5 \mathrm{~mm}-\mathrm{f} 0.1$ $\mathrm{mm} / \mathrm{rev}-\mathrm{Vc} 50 \mathrm{~m} / \mathrm{min}$
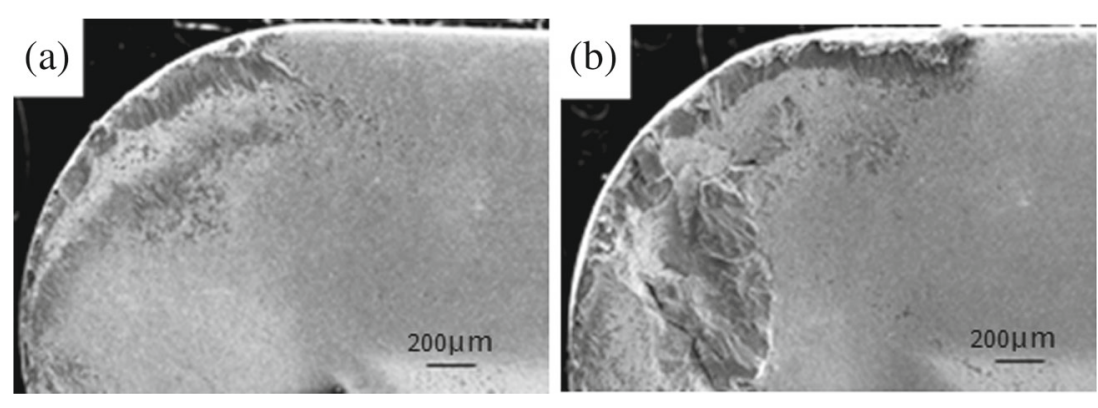

Fig. 20 Flank face SEM observation after $20 \mathrm{~min}$ of machining with cryogenic assistance (ap $1.5 \mathrm{~mm}-\mathrm{f} 0.1$ $\mathrm{mm} / \mathrm{rev}-\mathrm{Vc} 50 \mathrm{~m} / \mathrm{min}$ )

Fig. 21 Surface roughness evolution (ap $1.5 \mathrm{~mm}-\mathrm{f} 0.1$ $\mathrm{mm} / \mathrm{tr}-\mathrm{Vc} 50 \mathrm{~m} / \mathrm{min}$ )
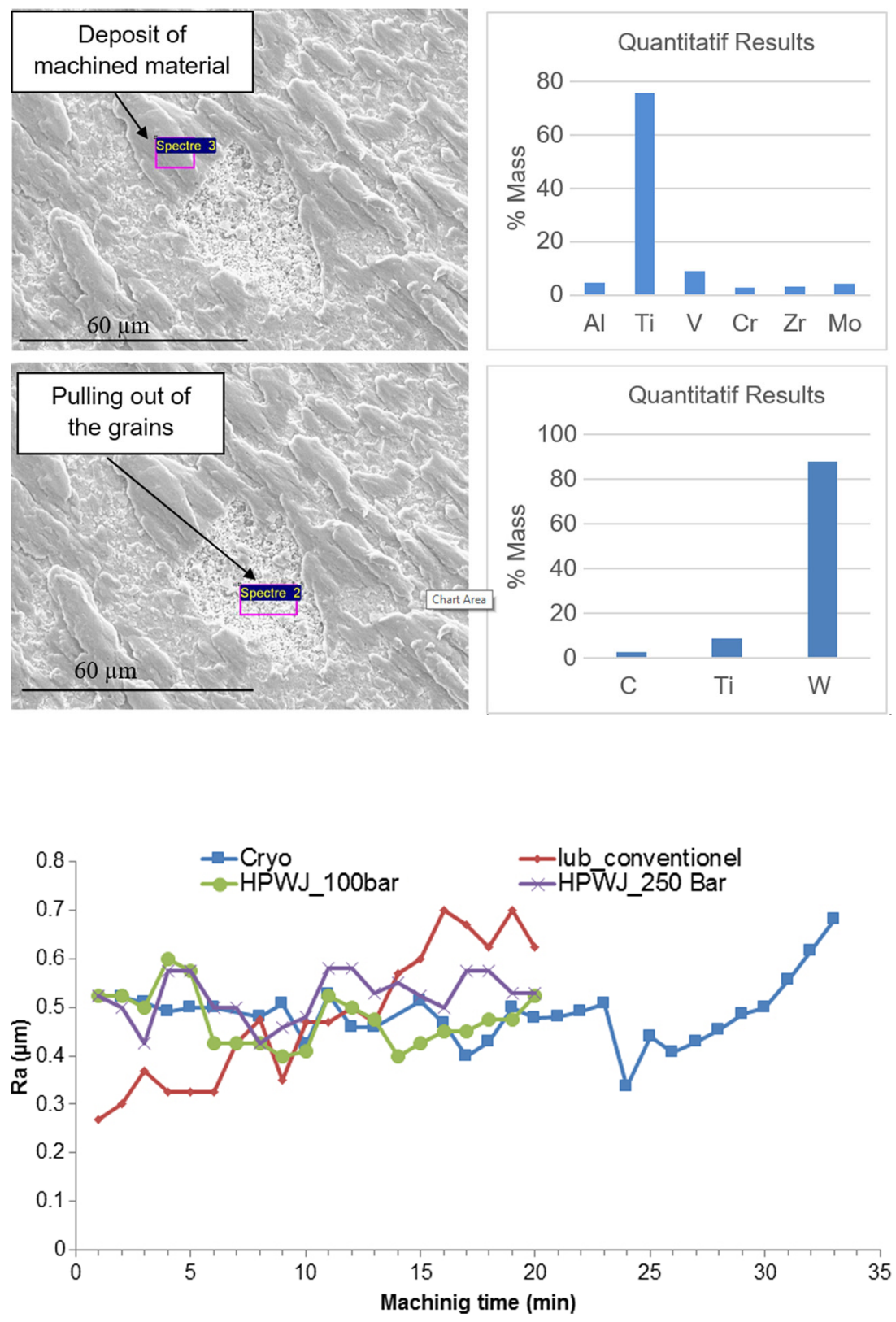
tion, the surface roughness starts from a lower value $(0.3$ $\mu \mathrm{m}$ ), but increases linearly until $0.7 \mu \mathrm{m}$ after $20 \mathrm{~min}$ (value obtained in cryogenic conditions at $33 \mathrm{~min}$ ).

With high-pressure water jet assistance, the roughness fluctuates in larger intervals compared to the case of cryogenic assistance. The work-piece surface shows scratches due to recycling fragments of chips, slipping between the cutting tool and the workpiece [12].

\section{Conclusion}

The research was conducted to study the effect of cryogenic assistance when machining titanium alloy Ti17 for different machining setups. The results can be grouped as follows:

- The cryogenic support increased the life of the tool relative to the conditional lubrication for all the tested combinations.

- For the cutting speed of $50 \mathrm{~m} / \mathrm{min}$, the lifetime increases sharply with cryogenic assistance. However, for a cutting speed of $90 \mathrm{~m} / \mathrm{min}$, the tool life falls sharply for both roughing and finishing tests. The gain with the cryogenic support becomes low.

- Cutting efforts are similar in cryogenic machining and conventional machining, while the friction coefficient is lower with cryogenic assistance. This seems to be due to the material hardening at low temperature.

- The comparative study between the HP water jet support at 100 and 250 bars led by Ayed and the cryogenic support showed that the cryogenic assistance is marginally more effective for a finishing operation (ap $1.5 \mathrm{~mm}$-f $0.1 \mathrm{~mm} / \mathrm{rev}-\mathrm{Vc} 50 \mathrm{~m} / \mathrm{min}$ ). However, in the roughing test (ap $3 \mathrm{~mm}-\mathrm{f} 0.3 \mathrm{~mm} / \mathrm{rev}-\mathrm{Vc} 50 \mathrm{~m} / \mathrm{min}$ ), HP water jet assistance is more effective; mainly because of the mechanical action of the water jet that provides cooling to the tip of the tool.

\section{References}

1. Arrazola P-J, Garay A, Iriarte L-M, Armendia M, Marya S, Maître FL (2009) MaChinability of titanium alloys (Ti6Al4V and Ti555.3). J Mater Process Technol 209:2223-30

2. Venugopal KA, Paul S, Chattopadhyay AB (2007) Growth of tool wear in turning of Ti-6Al-4V alloy under cryogenic cooling. Wear 262:1071-1078

3. Wang ZY, Rajurkar KP (2000) Cryogenic machining of hard-tocut materials. Wear 239:168-175

4. Dhananchezian M, Pradeep Kumar M (2011) Cryogenic turning of the Ti-6Al-4V alloy with modified cutting tool inserts. Cryogenics 51:34-40

5. Shane YH, Ding Y, Woo-cheol J (2001) Friction and cutting forces in cryogenic machining of Ti-6Al-4V. Int J Mach Tools Manuf 41:2271-2285

6. Bermingham MJ, Kirsch J, Sun S, Palanisamy S, Dargusch MS (2011) New observations on tool life, cutting forces and chip morphology in cryogenic machining Ti-6Al-4V. Int $\mathrm{J}$ Mach Tools Manuf 51:500-511

7. Ayed Y, Germain G, Ammar A, Furet B (2013) Degradation modes and tool wear mechanisms in finish and rough machining of Ti17 Titanium alloy under high-pressure water jet assistance. Wear 305(12):228237

8. Klinkova O, Rech J, Drapier S, Bergheau J-M (2011) Characterization of friction properties at the workmaterial/cutting tool interface during the machining of randomly structured carbon fibers reinforced polymer with carbide tools under dry conditions. Tribol Int 44:2050-2058

9. Ayed Y Approches expérimentales et numériques de l'usinage assisté jet d'eau haute pression : étude des mécanismes d'usure et contribution à la modélisation multi-physiques de la coupe-Thèse 2013-ENSAM-0056

10. Hua J, Shivpuri R (2005) Acobalt diffusion based model for predicting crater wear of carbide tools in machining titanium alloys. J Eng Mater Technol 127:136-144

11. Zhang S, Li JF, Deng JX, Li YS (2009) Investigation on diffusion wear during high-speed machining Ti-6Al-4V alloy with straight tungsten carbide tools. Int J Adv Manuf Technol 44:1725

12. Ayed Y, Germain G, Ammar A, Furet B (2015) Tool wear analysis and improvement of cutting conditions using the high-pressure water-jet assistance when machining the Ti17 titanium alloy. Precis Eng 42:294-301 